\title{
EM RAZÃO DE QUE SE EDUCAM AS CRIANÇAS: DA APRENDIZAGEM OU DO DESEMPENHO ESCOLAR?
}

\section{Why children educate: Learning or school performance?}

\author{
Karlane Holanda Araújo - Instituto Federal de Educação, Ciência e Tecnologia do \\ Ceará/Brasil \\ José Melinho de Lima Neto - Universidade Federal do Rio Grande do Norte/Brasil
}

\begin{abstract}
RESUMO: O objetivo deste artigo é discutir o cerne da questão em razão de que se educam as crianças, estabelecendo um confronto entre as concepções interacionistas acerca da aprendizagem e a premissa de maximizar o rendimento escolar infantil para obter melhor rentabilidade do investimento público. Partindo de um estudo teórico em diversas obras, conclui-se que as convicções de Piaget, Wallon e Vygostky, apesar de apresentem abordagens distintas a respeito do desenvolvimento, da aprendizagem e da educação da criança, partem do pressuposto de que a criança deve ser percebida como um todo integrado, e não restrita ao seu aspecto cognitivo. Entretanto, na prática, em função da supremacia da lógica neoliberal, que subordina a função social da educação para atender a demandas econômicas, as teorias interacionistas estão sendo desprezadas e subutilizadas nas escolas de educação infantil e ensino fundamental em detrimento da política contemporânea de avaliação educacional, que tende a massificar e a classificar nossas crianças em nome de uma educação de qualidade, a qual se legitima a partir dos resultados dos testes padronizados. Portanto, a ênfase na avaliação e nas provas externas distorce as finalidades da educação, porque nega o direito de aprendizagens, impõe um ideal de aluno e de criança, bem como não prevê o social e o afetivo da criança.
\end{abstract}

Palavras-chave: Aprendizagem. Criança. Rendimento escolar.

ABSTRACT: The purpose of this article is to discuss the crux of the matter because of that educate children, establishing a confrontation between interactionist conceptions about learning and the premise of maximizing children's school performance for improved return on public investment.We conclude that Piaget's beliefs, Wallon and Vygotsky, although they have different approaches, based on the assumption that the child should be seen as an integrated whole, and not restricted to its cognitive aspect. However, in practice, due to the supremacy of neoliberal logic, interactionist theories are being neglected and underutilized in preschools and elementary schools to the detriment of contemporary politics of educational assessment, which tends to popularize and to classify our children in the name of quality education, which is legitimate from the results of standardized tests. Therefore, the emphasis on evaluation and external tests distorts the purposes of education because it denies the right to learn, imposes a pupil and child ideal, and does not foresee the social and affective of the child.

Keywords: Learning. Child. School performance.

\section{INTRODUÇÃO}

Educação, Psicologia e Interfaces, Volume 3, Dossiê Inclusão e Diversidade, p. 83-97, 2019.

ISSN: 2594-5343.

DOI: https://doi.org/10.37444/issn-2594-5343.v3i4.202 
Atualmente, temos políticas educacionais estaduais e municipais que utilizam os resultados de desempenho escolar, provenientes das avaliações externas, para distribuição de "prêmios" às equipes das escolas e aos alunos, com base em índices e médias de proficiências alcançadas. As chamadas políticas de responsabilização forte, high-stakes, envolvem consequências institucionais cuja operacionalização implica a adoção de motivações financeiras, como é o caso dos programas de premiação por mérito, que concedem bonificação para os profissionais da educação brasileira de acordo com os resultados obtidos pelos alunos e pelas escolas em testes padronizados.

Nesse contexto, percebe-se que, cada vez mais, a avaliação externa orienta e determina os objetivos e a extensão das disciplinas (especialmente Língua Portuguesa e Matemática) na escola. Além disso, há a repercussão desse evento em outras categorias pedagógicas. Por meio da pressão crescente das avaliações externas, o professor e a escola elegem qual conteúdo e qual método de trabalho que mais atendem a essa lógica:“[...] as lógicas da eficácia e da qualidade que chegam à escola ocultam, sim, lógicas neoliberais" (CHARLOT, 2013, p. 46), evidenciando, assim, que:

[...] a educação tem sido influenciada pelos padrões do 'mercado', centra seus princípios e práticas na racionalidade mercantil, produtividade, competitividade e flexibilidade. Ajusta-se aos padrões da 'condição pós-moderna', motivada por valores midiáticos e por ideais de mistificação da realidade [...] (SILVA; LENARDÃO, 2010, p. 527).

O ideário de educação para todos norteia-se por parâmetros de produtividade, eficácia e qualidade. Nessa perspectiva, a função social da educação, no contexto neoliberal, subordina-se, de forma controlada, para responder às demandas do capital, e a escola fica com um papel estratégico de formar o discente para o processo de produção.

Para Horta Neto e Yannoulas (2012), essas políticas deixaram de se preocupar com o aprendizado para se preocupar preponderantemente com os resultados em testes de desempenho. É perceptível que a questão central desloca-se do sentido educativo da escola para o sentido de instruir sob a lógica de aprender para os testes. (CHARLOT, 2013).

Essa problemática se agrava quando falamos do ensino nas séries iniciais, especialmente no processo de alfabetização das crianças, porque é uma etapa de vida em 
Em razão de que se educam as crianças: da aprendizagem ou do desempenho escolar?

que o indivíduo encontra-se em fase de formação e constituição de sua subjetividade e identidade, tempo de certos cuidados e reconhecimentos, necessitando de cuidados afetivos, atenção e necessidades próprias da infância.

A infância, ao longo da história da humanidade, vem sendo estudada por vários teóricos que evidenciam as condições e as necessidades pertinentes ao desenvolvimento da criança. Neste artigo, buscaremos uma aproximação maior das ideias dos teóricos interacionistas com o intuito de nos apropriarmos de seus pressupostos centrais a respeito do desenvolvimento/aprendizagem da criança e, por conseguinte, avançarmos nas refutações em face dos modelos e das práticas educacionais brasileiras contemporâneas.

As concepções psicogenéticas dos estudiosos Jean Piaget (1896-1980), Henri Wallon (1879-1962) e Lev Vygotsky (1896-1934), embora apresentem abordagens distintas a respeito do desenvolvimento, da aprendizagem e da educação da criança, partem do pressuposto de que a criança deve ser percebida como um todo integrado, e não restrita ao seu aspecto cognitivo.

As teorias desses três expoentes interacionistas versam sobre desenvolvimento e aprendizagem da criança, explicitando como se dá a constituição da inteligência. Ante as ideias dos interacionistas, percebe-se que a formação da inteligência não é um ato isolado, acontece associada aos aspectos biológicos, motores, afetivos e psicossociais.

Entretanto, na prática, comumente, essas teorias estão sendo preteridas em nome de preparar as crianças para as avaliações externas, a fim de atingir níveis de proficiências desejáveis de leitura/escrita e de aparecer no topo do ranking nacional de desempenho escolar de qualidade.

Em razão disso, são pertinentes as seguintes questões: em nome de que se educam as crianças? Em nome da aprendizagem da criança e de sua formação ou em nome do desempenho escolar? Ao padronizar um suposto rendimento como adequado e necessário à sociedade vigente, determina-se um eixo padrão a que todas as crianças dentro da "normalidade" devem atender. Com efeito, aligeiram-se e pressionam-se às crianças a darem respostas que atendam a um padrão de eficácia e de qualidade de ensino. As crianças são comparadas entre si dentro da própria escola e entre escolas. Caso venham a apresentar algum desvio do padrão de "normalidade", 
designa-se a psicopatologia das aprendizagens e da adaptação escolar (JERUSALINSKY, 1999).

Diante dessa problemática, o presente artigo objetiva discutir o cerne da questão Em razão de que se educam as crianças, estabelecendo um confronto entre as concepções interacionistas acerca da aprendizagem da criança e a premissa de maximizar o rendimento escolar dos educandos para obter melhor rentabilidade do investimento público, a fim de evidenciar como a lógica da política de educação neoliberal, reproduzida no cenário da educação brasileira, distancia-se de uma educação voltada para o desenvolvimento integral da criança que respeita a maturidade e o ritmo da aprendizagem infantil, bem como as necessidades e os desejos do aprendiz.

\section{MATERIAL E MÉTODO}

O presente estudo é de natureza teórica e apoiou-se em autores renomados, como Piaget (1964), Wallon (1941), Vygotsky (1934), Charlot (2013), Shultz (1971), Freitas (2014), entre outros. A estrutura do artigo se encontra organizada em quatro seções. A terceira seção apresenta os resultados da pesquisa, e está dividida em duas subseções, a primeira aborda as concepções interacionistas de Piaget, Wallon e Vygotsky acerca do desenvolvimento e aprendizagem das crianças, e segunda subseção trata sobre a lógica neoliberal que dá formato às políticas educacionais brasileiras, especificamente as de avaliação educacional. A quarta e última seção, à guisa de conclusão, destaca os contrapontos desse confronto, trazendo à tona os descaminhos e os descompassos que vêm assolando a educação de nossas crianças. .

\section{DESENVOLVIMENTO E APRENDIZAGEM: DIALOGANDO COM AS CONCEPÇÕES INTERACIONISTAS}

Como dito anteriormente, a proposta desta seção é dialogar com os interacionistas Piaget, Wallon e Vygotsky, apresentando as proposições nucleares de cada um desses teóricos a respeito da relação desenvolvimento/aprendizagem da criança.

Partiremos, inicialmente, da concepção piagetiana, que rompeu com o inatismo e o empirismo, doutrinas que tinham, respectivamente, como lógica o fato 
Em razão de que se educam as crianças: da aprendizagem ou do desempenho escolar?

de que o conhecimento seria, exclusivamente, inato no indivíduo, ou que provinham unicamente da experiência.

Em seus resultados de pesquisas, Piaget declinou que a gênese do conhecimento está no próprio sujeito, construído na interação sujeito-objeto. No modelo piagetiano, o desenvolvimento humano é explicado segundo o pressuposto de que existe uma conjuntura de relações de fatores interdependentes entre o sujeito conhecedor e o objeto a conhecer e de que a elaboração do pensamento lógico demanda um processo interno de reflexão. Os fatores de desenvolvimento são complementares e envolvem mecanismos bastante complexos, tais como: o processo de maturação do organismo, a experiência com objetos, a vivência social e, sobretudo, a equilibração do organismo ao meio.

Piaget (2002), no escrito Seis Estudos de Psicologia, considera seis estágios do desenvolvimento humano que marcam o aparecimento motor, intelectual e afetivo. Cada estágio corresponde a uma hierarquia de condutas, correspondendo também às características momentâneas e secundárias, que são modificadas pelo desenvolvimento posterior, são eles:

$1^{\circ}$. O estágio dos reflexos, ou mecanismos hereditários, assim como das primeiras tendências instintivas (nutrições) e das primeiras emoções. $2^{\circ}$. O estágio dos primeiros hábitos motores e das primeiras percepções organizadas, como também dos primeiros sentimentos diferenciados. $3^{\circ}$. O estágio da inteligência sensório-motora ou prática anterior à linguagem), das relações afetivas elementares e das primeiras fixações exteriores da afetividade[...]; $4^{\circ}$. O estágio da inteligência intuitiva, dos sentimentos interindividuais espontâneos e das relações sociais de submissão ao adulto (de dois a sete anos, ou segunda parte); $5^{\circ}$. O estágio das operações da 'primeira infância' intelectuais concretas (começo da lógica) e dos sentimentos morais e sociais de cooperação (de sete a onze-doze anos de idade); $6^{\circ}$. O estágio das operações intelectuais abstratas, da formação da personalidade e da inserção afetiva e intelectual na sociedade dos adultos (adolescência) (PIAGET, 2002, p. 15).

Vale ressaltar que, embora todos os indivíduos vivenciem esses seis estágios na mesma sequência, o início e o término de cada um deles podem vir a sofrer variações em decorrência das características da estrutura biológica de cada indivíduo e da riqueza (ou não) dos estímulos proporcionados pelo meio ambiente em que ele estiver inserido.

Educação, Psicologia e Interfaces, Volume 3, Dossiê Inclusão e Diversidade, p. 83-97, 2019. ISSN: $2594-5343$.

DOI: https://doi.org/10.37444/issn-2594-5343.v3i4.202 
As contribuições de Piaget para a aprendizagem podem ser citadas, por exemplo: a possibilidade de estabelecer objetivos educacionais, uma vez que a teoria fornece parâmetros importantes sobre o "processo de pensamento da criança" relacionados aos estágios do desenvolvimento; a possibilidade de considerar o erro como estratégia usada pelo aluno em sua tentativa de aprendizagem de novos conhecimentos; e ainda a possibilidade de admitir que há diferentes estilos individuais de aprendizagem.

Na sequência, o diálogo será a respeito da concepção de Henri Wallon. Sua teoria considera o desenvolvimento da pessoa integrada ao meio em que está imersa, com os seus aspectos afetivos, cognitivos e motores também integrados.

Nessa esteira, Wallon aborda que, no desenvolvimento da pessoa, enfrentamse e implicam-se fatores de origem biológica e social. Os fatores biológicos são responsáveis pela sequência fixa que se verifica entre os estágios do desenvolvimento, os quais, todavia, não garantem uma homogeneidade no seu tempo de duração, e os fatores sociais, que constituem efeitos amplamente transformados pelas circunstâncias sociais nas quais se insere cada existência individual e mesmo por deliberações voluntárias do sujeito (GALVÃO, 1995).

No início, os fatores orgânicos são mais determinantes, porém, progressivamente, vão cedendo espaço aos fatores socioculturais. Wallon (2007) admite o organismo como condição primeira do pensamento, mas não constitui uma razão suficiente, visto que o objeto da ação mental vem do exterior, isto é, do grupo ou do ambiente no qual o indivíduo se insere. O sujeito é determinado, portanto, por uma dupla história, a de suas disposições internas, fisiológicas, e a das situações exteriores que encontra ao longo de sua existência. Para cada idade da criança, há uma estrutura orgânica em condição de maturação, que, associada às necessidades mais elementares da vida e ao meio externo, possibilita o desenvolvimento mental da criança, permitindo descrevê-lo em estágios sucessivos e integrados (WEREBE; BRULFERT, 1986), assim:

Ao mesmo tempo que, em cada etapa, se realiza um equilíbrio estável entre as possibilidades atuais e as condições de vida correspondentes, tendem também a operar-se mudanças cuja causa é estranha à exata relação funcional. Esta causa é orgânica. No desenvolvimento do indivíduo, a função desperta com o crescimento do órgão e o órgão precede-a muitas vezes de longe (WALLON, 1981, p. 49-50). 
Compreende-se que o fator orgânico de funcionamento é condição necessária para o desenvolvimento, mas não é suficiente ou independente, visto que as possibilidades atuais e as condições de vida da criança se manifestam também com igual importância. Desse modo, podemos acrescer que a indeterminação das práticas e necessidades de nossa vida cotidiana corroboram para a singularidade do desenvolvimento de cada criança. Apesar da carga genética, as circunstâncias culturais incidem no progresso mental de cada criança de forma diferenciada. Nessa perspectiva, o modelo walloniano concebe o desenvolvimento como um processo que envolve vários campos funcionais: afetividade, conhecimento (cognição/inteligência) motricidade e pessoa.

A integração desses três primeiros campos constitui o subconjunto, denominado por Wallon pessoa, que se expressa pela constituição do eu com o outro, passando pela conduta de oposição, aceitação, admiração e imitação do outro para fins de construto da identidade. Conforme Wallon, em qualquer momento, ou fase do desenvolvimento, a pessoa é sempre uma pessoa completa, que irá responder as situações de vida de acordo com a integração funcional dos campos, nos domínios do ato motor, afetivo e de conhecimento.

Os campos funcionais, movimento, emoções, inteligência e pessoa, são interdependentes. O desenvolvimento desses campos não acontece de maneira linear e contínua, mas por integração de novas funções e aquisições às anteriores. A acumulação quantitativa de funções culmina na evolução qualitativa das mesmas a partir de uma nova organização em que as dimensões motora, afetiva e cognitiva se integram de maneira diversa da fase anterior, alternando-se no exercício de predominância de uma sobre as demais. Assim, podemos definir o projeto teórico de Wallon como a elaboração de uma psicogênese da pessoa completa.

Uma reflexão extremamente relevante sobre as implicações da teoria de Wallon para a educação da criança é que desenvolvimento/aprendizagem se dá de acordo com suas condições de existência. O meio social e a cultura constituem as condições, as possibilidades e os limites de desenvolvimento para o organismo. Portanto, nesse prisma, a cognição é vista como parte da pessoa completa, que só pode ser compreendida integrada a ela, cujo desenvolvimento se dá a partir das condições 
orgânicas da espécie e é resultante da integração entre seu organismo e o meio, predominantemente o social.

Dando continuidade ao nosso diálogo com as teorias interacionistas, abordaremos alguns dos pressupostos centrais da concepção de Vygotsky acerca do desenvolvimento/aprendizagem da criança.

Vygotsky, em sua teoria sobre o processo de desenvolvimento do ser humano, superou a dicotomia entre o social e o individual, ideia presente nos pensamentos filosóficos e psicológicos de sua época. Sua abordagem foi orientada a partir do pressuposto de que o homem é um ser biológico, histórico e social. Sendo assim, seus estudos consideram o indivíduo inserido na sociedade, com ênfase no aspecto sóciohistórico e na relação do homem com o outro no espaço social (VYGOTSKY, 1996).

Para Vygotsky, o ser humano é um sujeito social em essência, não podendo ser compreendido fora do âmbito social. Assim, o ponto de vista de Vygotsky é o de que:

[...] o desenvolvimento humano é compreendido não como a decorrência de fatores isolados que amadurecem, nem tampouco de fatores ambientais que agem sobre o organismo controlando seu comportamento, mas sim como produto de trocas recíprocas, que se estabelecem durante toda a vida, entre indivíduo e meio, cada aspecto influindo sobre o outro (NEVES; DAMIANI, 2006, p. 7).

Nessa esteira, para Vygotsky, não é suficiente ter todo o aparato biológico da espécie para realizar uma tarefa se o indivíduo não participa de ambientes e práticas específicas que propiciem essa aprendizagem. Vygotsky (2010) defende que o único educador capaz de formar novas reações no organismo é a sua própria experiência, por meio da qual é possível a pessoa educar-se e modificar suas relações inatas. $\mathrm{O}$ ambiente dá condições para o surgimento de uma nova reação, que depende sempre de um embate entre o organismo e o meio.

A criança não possui, por si só, instrumentos para percorrer sozinha o caminho do desenvolvimento, ela dependerá de suas aprendizagens mediante as experiências a que foi exposta. "No processo educacional, a experiência pessoal do aluno é tudo[...], o meio social é a verdadeira alavanca do processo educacional, e todo o papel do mestre consiste em direcionar essa alavanca" (VYGOTSKY, 2010, p. 65).

Desenvolvimento e aprendizagem dizem respeito às experiências do sujeito no mundo com base nas interações, assumindo o pressuposto da natureza social do 
desenvolvimento e do conhecimento especificamente humano. Essa interação e sua relação com a imbricação entre os processos de ensino e aprendizagem podem ser mais bem compreendidos quando nos remetemos ao conceito de Zona de Desenvolvimento Proximal (ZDP). Para Vygotsky (1996), a ZDP é reconhecida como a distância entre o nível de desenvolvimento real, ou seja, aquilo que a criança já é capaz de fazer de forma independente, e o nível de desenvolvimento potencial, demarcado por aquilo que a criança é capaz de realizar para solucionar problemas a partir da colaboração de um parceiro mais experiente.

De acordo com Vygotsky, o processo de aprendizagem que ocorre na ZDP deve ser olhado por uma óptica prospectiva, ou seja, não se deve focalizar o que a criança já aprendeu, mas sim o que ela está aprendendo. São as aprendizagens que ocorrem na ZDP que fazem com que a criança se desenvolva ainda mais, " [...] ao dar um passo no aprendizado, a criança dá dois no desenvolvimento" (VYGOTSKY, 1996, p. 109). Como tal, é uma transformação constante na trajetória das crianças, por isso dizemos que, para Vygotsky, desenvolvimento e aprendizagem são processos indissociáveis, interdependentes e recíprocos.

Em face dos estudos de Vygotsky sobre desenvolvimento/aprendizagem, percebemos que suas ideias se contrapõem às concepções vigentes à época, visto que a aprendizagem não é tida como uma mera aquisição e memorização de informações, mas como um processo interno, ativo e interpessoal.

Diante das concepções de cada um desses interacionistas, identificamos ora diferenças, ora pontos em comum. Aqui, interessa-nos evidenciar as semelhanças, os aspectos convergentes entre as demais teorias acerca do desenvolvimento/ aprendizagem da criança, pois esses aspectos apontam em direção de uma prática educacional integrada, que leva em conta a carga genética, mas também as circunstâncias sociais do indivíduo; admite a interação social como elemento promissor da aprendizagem;prevê a importância da afetividade para o desenvolvimento psíquico e cognitivo da criança; tem o aluno como participante da construção do conhecimento, coautor ativo e questionador; considera ritmos diferentes de desenvolvimento e de aprendizagem, sendo os estágios referências relativas e variáveis, em dependência de características individuais e das condições de existência. 
Esses aspectos deveriam ser artefatos educacionais do processo de ensinoaprendizagem da educação básica brasileira, principalmente do ensino fundamental, no entanto estão sendo desprezados, uma vez que a política educacional brasileira supervaloriza os resultados das avaliações externas e as proficiências alcançadas pelos alunos e, por conseguinte, acaba pressionando os professores a adotarem práticas pedagógicas contrárias aos pressupostos defendidos pelos interacionistas.

A fim de ampliarmos nossa compreensão a respeito desse descaminho pedagógico que a política de avaliação educacional brasileira vem provocando na educação das crianças, a seção seguinte discutirá a respeito da lógica de aprender para os testes.

\section{DESEMPENHO ESCOLAR: A LÓGICA DE APRENDER PARA OS TESTES PADRONIZADOS}

A década de 1990 ficou marcada pela implementação de políticas neoliberais tanto no Brasil como em diversos países. A nova ordem mundial, intitulada de globalização econômica, incidiu na reestruturação produtiva, na consolidação do neoliberalismo e na reconfiguração do papel do Estado.

O fenômeno da globalização fez ressurgir o capitalismo com uma nova roupagem, alicerçado em critérios de eficiência e de eficácia econômica de acordo com os interesses do mercado, influenciando o campo da educação de modo significativo (ANTUNES; ALVES, 2004).

Imprimiu-se uma reforma na regulamentação das políticas educativas, com programas educacionais que focalizam a escola como unidade do sistema, transformando-a em núcleo de gestão e de planejamento. Tais programas e projetos têm sido financiados por organismos multilaterais, como o Banco Mundial, e conduzidos por órgãos de cooperação técnica, como o Fundo das Nações Unidas para a Infância (Unicef) e a Organização das Nações Unidas para a Educação, a Ciência e a Cultura (Unesco). Segundo Freitas (2004) e Santos (2004), esses programas são aplicados diretamente nas escolas, tanto no sentido de incentivar ações quanto no sentido da avaliação dos resultados.

Essa reforma está alicerçada na Teoria do Capital Humano (TCH), formalizada por Schultz (1971), na qual evidencia que o aumento no investimento no capital humano é um importante fator para o desenvolvimento econômico. 
Desse modo, a TCH postula que, quanto mais se investir em apreensão de conhecimentos, maior será o valor agregado para o indivíduo atender às necessidades/exigências do mercado e maior será a chance de ele obter o sucesso pessoal. Por outro lado, a TCH coloca esse feito como responsabilidade individual, em que vai depender do interesse, da aptidão e do esforço individual para se atingir o mérito. Nesse sentido, a sociedade tende a se dividir entre os aptos e os não aptos, uma vez que:

[...] os indivíduos que mais merecem por seu esforço e maior escolaridade devem assumir o topo da hierarquia social e ter melhor situação econômica e política. Ocorre a relação direta entre melhor qualificação profissional e maior escolarização de uma pessoa com a diminuição de sua pobreza (SILVA; LENARDÃO, 2010, p. 519).

A partir da concepção da TCH, padronizar, avaliar e controlar são as palavras de ordem do sistema educacional e se desdobram nos processos pedagógicos da escola básica, através do currículo mínimo, das avaliações externas e das políticas de gestão por resultados.

Aqui daremos ênfase ao quesito avaliação, que, nos últimos 20 anos, tem ocupado um lugar central na escola. Exemplo disso é o cabedal de instrumentos avaliativos institucionalizados pelo sistema educacional brasileiro, como: a Prova Brasil, o Exame Nacional do Ensino Médio (Enem), o Sistema de Avaliação da Educação Básica (Saeb), a Avaliação Nacional da Alfabetização (ANA) e outros que confirmam a posição de centralidade da categoria da avaliação no âmbito pedagógico.

As pressões externas da avaliação levam a escola a criar mecanismos concorrenciais internos de controle sobre as crianças, como a divulgação das listagens de desempenho nos exames externos que são afixadas nas salas de aula ou em outros locais da escola, as quais acabam classificando as crianças e gerando um clima escolar competitivo e desigual. Não obstante, associado a isso, o docente sente-se pressionado pelo sucesso da criança nas provas da avaliação externa para a obtenção de bônus ou de remuneração variável em seu salário, isso interfere irremediavelmente na relação professor-aluno e sela, muitas vezes, o destino da criança (FREITAS, 2014).

O fato é que, em nome da política de alfabetização na idade certa, o ensino das competências e das habilidades de leitura passou a assumir a lógica produtivista, tratando a educação, como diz Charlot $\left(201^{3}\right)$, sob a óptica do custo-benefício, da lógica

Educação, Psicologia e Interfaces, Volume 3, Dossiê Inclusão e Diversidade, p. 83-97, 2019.

ISSN: $2594-5343$.

DOI: https://doi.org/10.37444/issn-2594-5343.v3i4.202 
de aprender para os testes, em que o saber deixa de ser a finalidade da ação para se situar como meio para se atingir os fins, tais como as metas e os resultados. Nessa vertente, o aprendiz, em especial a criança, é tido como "moeda de troca". A criança avaliada “[...] se torna um objeto de troca, na medida em que seu 'trabalho' pode implicar um plus monetário para a escola” (PASSONE, 2014, p. 3).

É comum o professor criar, seja mediante o padrão de "normalidade", seja mediante os resultados das proficiências desejáveis, uma autoimagem da criança, um standard, um sujeito infantil suposto como normal. Ou as crianças dão conta das tarefas pré-definidas pelo "mundo globalizado", ou estão fora, descartadas e fadadas ao fracasso escolar.

Em síntese, desde que os critérios de sucesso e fracasso da política educacional brasileira passaram a ser definidos por metas e parâmetros de análise, monitoramento e avaliação externa do produto, as práticas docentes tendem a distanciarem-se de uma educação voltada para o desenvolvimento integral da criança, que respeita a maturidade e o ritmo da aprendizagem infantil, bem como as necessidades e os desejos do aprendiz, pressupostos defendidos por Piaget, Wallon e Vygotsky.

Em face disso, os educandos que não se saem bem nos testes são estigmatizados por não se adequarem ao padrão de qualidade preestabelecido. Logo, aqueles alunos que se desviam do standard, da normalidade, do alcance do bom desempenho, sofrem com a discriminação e o preconceito de serem considerados discentes não aptos às competências e habilidades exigidas pela sociedade vigente.

Com efeito, temos visto a rotulação e estigmatização das crianças por não se saírem bem nos testes estandardizados, culpabilizando-as pelo fracasso, abstraindo condições orgânicas, psicossociais e culturais que envolvem o processo de aprendizagem dos estudantes defendidas pelos interacionistas.

\section{CONSIDERAÇÕES FINAIS}

A partir desse confronto entre as concepções interacionistas acerca da aprendizagem da criança e a premissa dominante de maximizar o rendimento escolar das crianças para obter melhor rentabilidade do investimento público, é possível considerar que o ideário neoliberal chega à escola, modelado por meio do currículo, da 
Em razão de que se educam as crianças: da aprendizagem ou do desempenho escolar?

avaliação e das políticas de reconhecimento e de premiação, a qual tende a padronizar e a controlar a cultura escolar, definindo o dia a dia da escola.

Em consequência, as concepções interacionistas de Piaget, Wallon e Vygotsky, estão sendo desprezadas e subutilizadas nas escolas de educação infantil e ensino fundamental em detrimento da política contemporânea de avaliação educacional, que tende a massificar e a classificar nossas crianças em nome de uma educação de qualidade, que se legitima a partir dos testes de proficiência em Língua Portuguesa e Matemática.

Essa realidade é paradoxal, visto que apesar dos governos terem investindo tempo e aplicado recursos, tão escassos, nos sistemas de avaliação em massa, as evidências nos têm mostrado os baixos impactos efetivos na melhoria da qualidade do ensino e os altos riscos que a política de avaliação educacional representa para prática escolar e para o ato educativo em si. Portanto, a ênfase na avaliação e nas provas externas distorce as finalidades da educação, porque nega o direito de aprendizagens, impõe um ideal de aluno e de criança, bem como não prevê o social e o afetivo da criança. Conclui-se que há um descompasso sobre a verdadeira razão de educá-las. É preciso dar voz às crianças ou falar em favor delas, urge tornar visível a crítica realidade dos fins que movem a educação infantojuvenil brasileira.

\section{REFERÊNCIAS BIBLIOGRÁFICAS}

ANTUNES, R.; ALVES, G. As mutações no mundo do trabalho na era da mundialização do capital. Revista de Educação \&Sociedade, Campinas, v. 25, n. 87, p. 335-351, 2004.

CHARLOT, B. Da relação com o saber às práticas educativas. São Paulo: Cortez, 2013.

FREITAS, L. C. A avaliação e as reformas dos anos de 1990. Educação \& Sociologia, Campinas, v. 25, n. 86, p. 133-170, 2004.

FREITAS, L. C. Os reformadores empresariais da educação e a disputa pelo controle do processo pedagógico na escola. Educação \& Sociedade, Campinas, v. 35, n. 129, p. 1085-1114, 2014.

GALVÃO, I. Henri Wallon: uma concepção dialética de desenvolvimento infantil. Petrópolis: Vozes, 1995.

Educação, Psicologia e Interfaces, Volume 3, Dossiê Inclusão e Diversidade, p. 83-97, 2019.

ISSN: 2594-5343.

DOI: https://doi.org/10.37444/issn-2594-5343.v3i4.202 
HORTA NETO, J. L.; YANNOULAS, S. C. A emergência da avaliação externa como organizadora da política educacional. In: Encontro Estadual da ANPAE,12., 2012, Campinas.Anais...Campinas, 2012. p. 166-180.

INEP. Saeb. Brasília, DF: Inep, 2013. Disponível em: <portal.inep.gov.br/web/saeb/aneb-e-anresc>. Acesso em: 14 jun. 2015.

JERUSALINSKY, A. Psicanálise e desenvolvimento infantil: um enfoque transdisciplinar. Porto Alegre: Artes e Ofícios, 1999.

LA TAILLE, Y. et al. Piaget, Vygotsky e Wallon: teorias psicogenéticas em discussão. São Paulo: Summus, 1993.

MARX, K.Manuscritos econômicos-filosóficos. São Paulo: Martin Claret, 2004.

NEVES, R. A.; DAMIANI, M. F. Vygotsky e as teorias da aprendizagem.UNI revista, [S.l.], v.1, n. 2, p. 1-10, 2006.

PASSONE, E. F. K. Quem avalia os avaliadores: questões acerca da política de incentivos por resultados escolares. In: Colóquio Internacional do LEPSI, 10., 2014, São Paulo.Anais...São Paulo: USP, 2014.

PIAGET, J. Epistemologia genética. Petrópolis: Vozes, 1971.

PIAGET, J. Seis estudos de psicologia. Rio de Janeiro: Forense Universitária, 2002.

SANTOS, L. L. C. P. Formação de professores na cultura do desempenho. Educação \& Sociedade, Campinas, v. 25, n. 89, p. 1145-1157, 2004.

SCHULTZ, T. W. O capital humano: investimentos em educação e pesquisa. Rio de Janeiro: Zahar, 1971.

SILVA, E. C.; LENARDÃO, E. Teoria do capital humano e a relação educação e capitalismo. In: Seminário de Pesquisa em Ciências Humanas, 8., 2010, Londrina. Anais... Londrina: UEL, 2010. p. 515-529.

VYGOTSKY, L. A formação social da mente. Rio de Janeiro: Martins Fontes, 1996.

VYGOTSKY, L. Psicologia pedagógica. São Paulo: Martins Fontes, 2010.

WALLON, H. A evolução psicológica da criança. Lisboa: 70, 1981.

WALLON, H. A evolução psicológica da criança. São Paulo: Martins Fontes, 2007.

WEREBE, M. J. G.; BRULFERT, J. N. (Org.). Henri Wallon: psicologia. São Paulo: Ática, 1986. 
Em razão de que se educam as crianças: da aprendizagem ou do desempenho escolar?

\section{Credenciais da/os autora/es}

ARAÚJO, Karlane Holanda. Professora no Instituto Federal de Educação, Ciência e Tecnologia do Ceará, graduada em Pedagogia (INET) e em Ciência Sociais (UNIFOR), Mestre em Educação Brasileira (UFC). E-mail: Karlane.araujo@ifce.edu.br

LIMA NETO, José Melinho de. Professor na Universidade Federal do Rio Grande do Norte, graduado em Matemática (UVA), Mestre em Educação Brasileira (UFC). E-mail:

j.mlneto@outlook.com

Endereço para correspondência: Karlane Holanda Araújo. Rua: Nove, nº92, Apto 1032, Bloco C. Bairro: Tabapuá. CEP: 61635270, Caucaia/Ce. E-mail:Karlane.araujo@ifce.edu.br.

Como citar este artigo: ARAÚJO, Karlane Holanda. LIMA NETO, José Melinho de.

Em razão de que se educam as crianças: da aprendizagem ou do desempenho escolar? .

Educação, Psicologia e Interfaces, v. 3, Dossiê Inclusão e Diversidade, p. 83-97,, 2019. DOI: https://doi.org/10.37444/issn-2594-5343.v3i4.202

Recebido: 07/08/2019.

Aceito: 20/11/2019.

Educação, Psicologia e Interfaces, Volume 3, Dossiê Inclusão e Diversidade, p. 83-97, 2019.

ISSN: 2594-5343.

DOI: https://doi.org/10.37444/issn-2594-5343.v3i4.202 